\title{
VALUES OF PHYSICAL CULTURE: STRUCTURE, CHARACTERISTICS
}

\section{(C) 2017}

Korovin Sergey Semenovich, doctor of pedagogical sciences, professor of Theory and Methodology of Sports, Adaptive Physical Culture and Medico-Biological Foundations of Physical Education Department Maloroshvilo Lilia Nailievna, candidate of pedagogical sciences, associate professor, head of Physical Culture Department Orenburg State Pedagogical University (Orenburg, Russian Federation)

Abstract. Target development and justification of established theories, technologies, and structures of educational systems is the formation of cultural characteristics of the individual at all stages of continuous education, which reflects the mentality of society and the state (as a result) - development of the value-oriented «overbiological» programs of human activities, knowledge, abilities and skills of their practical and creative use. It is very important to develop components (their characteristics) of the individual basic culture, which include moral, aesthetic, labor, civil, intellectual (cognitive) and physical cultures. Nowadays, the structure of physical culture values can be represented by a group of material (the human body, sports equipment, sports facilities, mass media, scientific equipment, environmental - natural factors), spiritual (physical, intellectual, pedagogical, mobilization, intention) and artistic (a set of artistic images and works that reflects the values of the material and spiritual spheres of the society) values. The optimum ratio of the used physical culture values is believed to ensure the quality of the content of sports activity and as a consequence - the development of culture among students.

Keywords: culture; education; physical culture; physical education; personality development; basic culture components; physical culture of personality; physical culture values structure; characteristic of material; spiritual and artistic values of physical culture.

\section{ПРОФЕССИОНАЛЬНОЕ ОБЩЕНИЕ НА ИНОСТРАННОМ ЯЗЫКЕ: НЕКОТОРЫЕ ВОПРОСЫ ПРОЕКТИРОВАНИЯ ПРАКТИКУМА ДЛЯ БАКАЛАВРОВ}

\section{(C) 2017}

Малова Наталья Владимировна, кандидат педагогических наук, доцент кафедры иностранных языков Самарский государственный институт культуры (2. Самара, Российская Федераиия)

\footnotetext{
Аннотация. В статье обсуждается одна из таких актуальнейших задач подготовки современного специалиста, как формирование его готовности к ведению профессиональной коммуникации на иностранном языке. Запросы практики закономерно находят свое отражение в формировании учебных планов и программ высшего профессионального образования. Автором демонстрируется актуальность поставленной задачи в связи с постоянно изменяющимися требованиями к осуществлению иноязычных профессиональных коммуникаций с акцентом на их компьютерно-опосредованную часть. Для этого обозначаются два основных подхода к организации обучения студентов в вузе: изменение структуры, содержания, методики учебной дисциплины «Иностранный язык» и разработка новых дисциплин учебного плана. В рамках второго подхода достаточно подробно рассмотрен процесс проектирования учебно-методического комплекса для курса-практикума профессионального общения на основе процессного подхода. Описание этапов снабжено конкретными примерами разработки для профиля подготовки «Звукорежиссура культурно-массовых представлений и концертных программ». В статье подчеркивается важность использования профессиональных навыков будущих специалистов для повышения эффективности учебного процесса, в частности, разработки авторских аудио- и видеоматериалов. Показано, что разработанный в соответствии с предлагаемой схемой практикум для аудиоинженеров успешно используется в учебном процессе Самарского государственного института культуры.

Ключевые слова: методическое проектирование; иностранный язык; подготовка бакалавров; интерактивное обучение; тезаурус студента; ситуации профессионального общения; видеоконтент; подготовка звукорежиссера; практикум профессионального общения на иностранном языке; аудиоконтент; сценарий профессионального общения; контекстный подход.
}

Глобализация современного мира, информатизация социума и взрывной рост доступности современных информационно-коммуникационных технологий закономерно трансформирует иноязычное профессиональное общение из специфической в повседневную задачу. Консультации по скайпу с производителями импортного оборудования, изучение многочисленных мануалов и технических руководств, общение со службами технической поддержки - вот далеко не полный перечень ситуаций, в ко- торых современный специалист применяет свои навыки общения на иностранном языке. Запросы практики закономерно находят свое отражение в формировании учебных планов и программ высшего профессионального образования. Особую важность при этом приобретает проектирование и корректная реализация интерактивного обучения иностранному языку в контексте будущей профессиональной деятельности выпускников-бакалавров неязыкового вуза [1]. 
Малова Н.В.

При этом можно выделить два основных подхода к организации подготовки бакалавров этой категории:

- изменение структуры, содержания, методики дисциплины «Иностранный язык» базового блока;

- разработка новых дисциплин учебного плана, сфокусированных на профессиональных аспектах иноязычного общения.

Второй подход, реализуемый в Самарском государственном институте культуры (на примере дисциплины «Практикум профессионального общения»), видится нам более перспективным из-за значительной дифференциации в подготовке студентов по иностранному языку на третьем курсе.

Анализ лингвистической, филологической и психолого-педагогической литературы позволяет констатировать как актуальность задачи методического проектирования курсов, формирующих языковую компетентность специалистов в ситуациях профессионального общения [2], так и целый ряд проблем, с этим связанных [3-5]. Среди них следует выделить дидактические (отсутствие системного подхода при проектировании) и филолого-лингвистические (выделение ключевого тезауруса профессиональной области, поиск и отбор массива аутентичного языкового материала), а также методические (применение интерактивных методов и технологий обучения, организация самостоятельной работы студентов, организация эффективного обучающего контроля, совместная реализация принципов доступности и профессиональной направленности текстов). Заметим также, что традиционно ключевым дидактическим элементом выступает именно текст, что подтверждается в целом ряде исследований [6; 7]. Существенное влияние на процессы проектирования оказывает также традиционно высокий уровень абстрагирования в таких исследованиях.

Между тем практический опыт показывает, что иноязычное профессиональное общение достаточно специфично даже для «родственных» специальностей. Так, для программистов, системных администраторов иноязычное общение сосредоточено, прежде всего, на изучении документации на иностранном языке, взаимодействии в профессиональных сообществах. При этом подавляющая часть терминологии предметной области напрямую заимствована из английского языка, а грамматические конструкции упрощены из-за значительного количества индийских, китайских разработчиков в сообществе. Специалисты технической поддержки при этом куда чаще общаются с конечными пользователями, зачастую используя английский как язык межнационального общения. Таким образом, сложно разработать единую схему курса.

С нашей точки зрения, целесообразно унифицировать не сам практикум, а процедуру его построения (процессный подход к качеству). При этом следует учитывать, что построение идеальной структуры курса на первом этапе невозможно, так как развитие структуры и содержания будет идти по девятиэтапной спирали.
Эman 1. Анализ типичных ситуаций (сценариев) иноязычного профессионального общения. Источниками информации на данном этапе выступают: интервью с уже работающими специалистами; опрос студентов (в том числе работающих) старших курсов об их карьерных планах; анализ публикаций; анализ вакансий и резюме; анализ видеоматериалов [8], блогов, записей в социальных сетях, форумах профессиональной направленности; анализ учебных курсов и программ других вузов.

Проведенный анализ для профиля подготовки «Звукорежиссер» позволил выявить примерную структуру иноязычного общения специалистов этого профиля. Так как количество опрошенных сравнительно невелико (23 студента и 7 специалистов), результат не является статистически значимым, но дает общее представление о коммуникациях звукорежиссера на иностранном (английском) языке. Для получения оценок использовался метод воркшопа, согласование выполнялось в процессе работы. Результаты представлены в табл. 1 .

Таблица 1 - Ситуации иноязычного общения в деятельности звукорежиссера

\begin{tabular}{|l|c|c|}
\hline \multicolumn{1}{|c|}{\begin{tabular}{c} 
Сценарий \\
\multicolumn{1}{|c|}{$\begin{array}{c}\text { иноязычного } \\
\text { общения }\end{array}$}
\end{tabular}} & \multicolumn{2}{|c|}{$\begin{array}{c}\text { \% соотношение } \\
\text { поению }\end{array}$} \\
\cline { 2 - 3 } & специалистов & студентов \\
\hline $\begin{array}{l}\text { Чтение документации } \\
\text { по оборудованию и } \\
\text { программных продук- } \\
\text { тов }\end{array}$ & $50 \%$ & $12 \%$ \\
\hline $\begin{array}{l}\text { Общение на форумах, } \\
\text { в социальных сетях }\end{array}$ & $10 \%$ & $38 \%$ \\
\hline $\begin{array}{l}\text { Просмотров видеоуро- } \\
\text { ков, видеоинструкций }\end{array}$ & $15 \%$ & $20 \%$ \\
\hline $\begin{array}{l}\text { Стажировки, совмест- } \\
\text { ная работа }\end{array}$ & $10 \%$ & $25 \%$ \\
\hline Прочее & $5 \%$ & $5 \%$ \\
\hline
\end{tabular}

Данные табл. 1 показывают, что студенты более оптимистично настроены по отношению к доле интерактивного, живого общения с носителями языка (стажировки, социальные сети) и недооценивают роль рутинной работы по знакомству с документацией.

Этап 2. Выявление инвариантного тезауруса профессионального общения с учетом специфики [9]. Эта процедура будет более эффективна, если заранее кластеризовать тезаурус. Для аудиоинженеров необходимую лексику можно сгруппировать, например, так, как представлено на рис. 1.

Полный перечень терминов с группировкой по темам приведен в работе [10]. Отметим при этом, что методы структурирования тезауруса могут быть различны (например, для ИТ-специалистов можно рассматривать лексику для программирования, баз данных, программных продуктов, сетевых технологий), однако определение основных объектов, субъектов и способов их взаимодействия в предметной области должно осуществляться во взаимодействии со специалистами. 
Этап 3. Подбор адаптированных и аутентичных материалов, охватывающих заданную терминологию.

Работы данного этапа выполняются преподавателем постоянно в ходе учебного процесса и практически не нуждаются в комментариях. Отметим лишь, что зачастую адаптированные материалы преподаватель разрабатывает самостоятельно, аутентичные же материалы, особенно аудио- и видеоматериалы (например, [11-13]), требуют предварительной экспертизы в части соответствия выбранному для изучения диалекту языка (английский или американский), произношения диктора, используемого тезауpyca).

Эman 4. Выбор методов и технологий обучения на базе контекстного подхода [14] с учетом ситуации общения. Характеризуя данный этап, отметим, что в соответствии с контекстным подходом подбор совокупности методов осуществляется на основе результатов первого этапа (см. табл. 1), но с учетом реального уровня возможностей обучаемых. Некоторые виды работ (например, стажировки) можно имитировать средствами ролевых и деловых игр.

Этаn 5. Использование возможностей описываемого профиля подготовки бакалавров для повышения эффективности образовательного процесса. Практикум профессионального общения, как правило, изучается на старших курсах бакалавриата, когда студенты уже выработали значительный объем профессиональных навыков и компетенций. Эти навыки можно и нужно использовать в процессе изучения иностранного языка. Для специальности «Аудиоин- женер» такими заданиями могут выступать: запись собственного аудио по тексту, трансформация машинного чтения в аналог естественной речи, наложение звуковых эффектов, характерных для сцены, просмотр обучающего видео с выделением фрагментов, содержащих изучаемые термины, составление видеокаталога звуковых эффектов и их названий, создание английских/русских субтитров для учебного видео с помощью преподавателя.

Эman 6. Выбор технологий для организации текущего, рубежного и итогового контроля, организации самостоятельной работы обучающихся. Эта процедура достаточно подробно изучена [1], поэтому мы отметим лишь то, что целесообразно для исследования проблемы нашей статьи, в том числе использование электронного портфолио [15], включающего лучшие результаты выполнения творческих, профессионально-ориентированных заданий обучающимися. Шестой этап выступает последним в первичной разработке учебно-методического комплекса для практикума профессионального общения. Однако необходимо подчеркнуть, что совершенствование методических материалов - непрерывный процесс. Поэтому отметим еще три этапа.

Эman 7. Проведение дополнительных занятий и дополнительный контроль результатов.

Этап 8. Мониторинг и оперативное внесение коррективов в учебный курс.

Эman 9. Периодический мониторинг необходимых ресурсов сети Интернет и внесение корректировок в учебный курс.

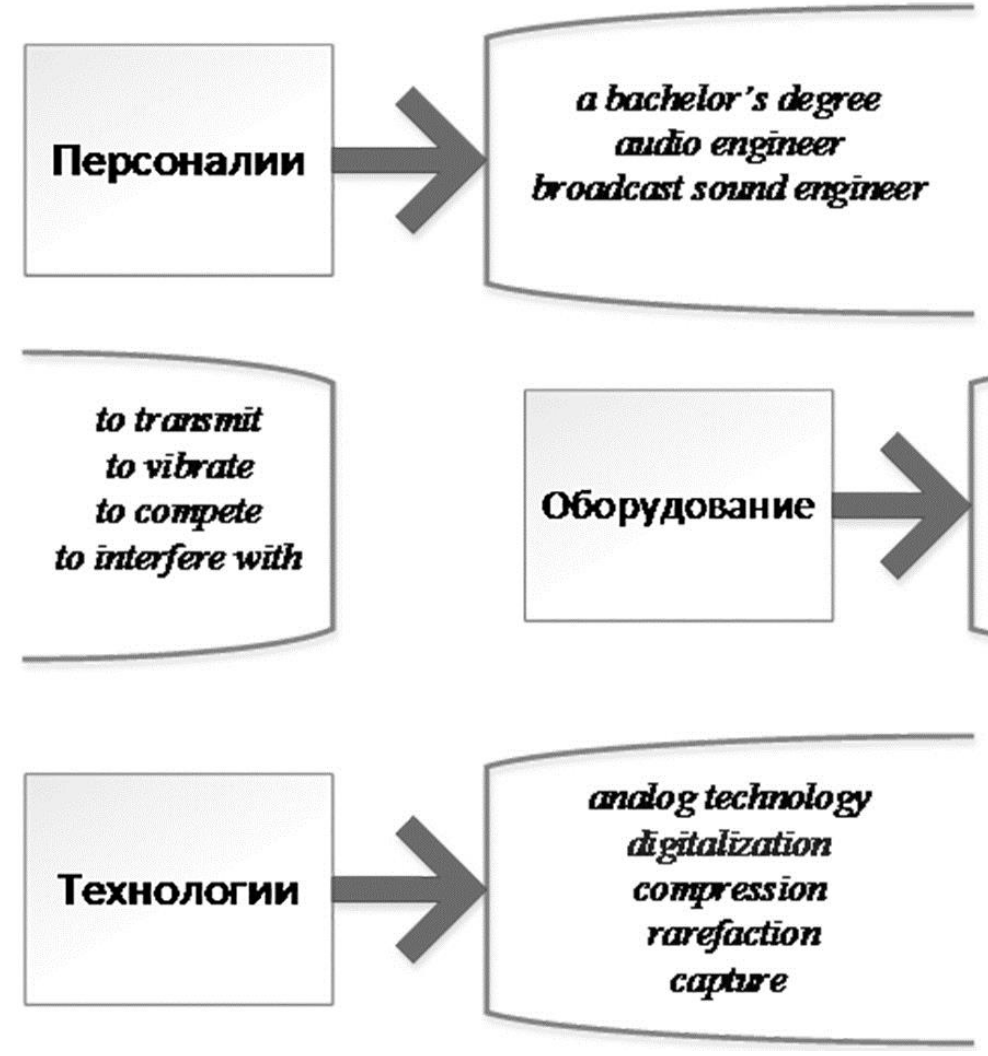

Рисунок 1 - Кластеризация тезауруса звукорежиссера

С учетом вышеизложенного можно сделать вывод о том, что источниками корректировок процесса проектирования практикума для бакалавров профиля подготовки «Звукорежиссура культурно-массовых представлений и концертных программ» могут служить как результаты апробации и внедрения практикума (например, закрепление усваиваемых терминов посредством дополнительных заданий), так и осу- 
ществляемый на девятом этапе мониторинг сети Интернет, технической документации, профессионального сообщества с целью выявления новых объектов, терминов, понятий, жаргонизмов, дополнения и расширения учебно-методических материалов. Разработанный в соответствии с предлагаемой схемой практикум для подготовки аудиоинженеров успешно используется в учебном процессе Самарского государственного института культуры.

\section{СПИСОК ЛИТЕРАТУРЫ:}

1. Трошкина В.И. Инновационные процессы в обучении иностранному языку в неязыковом вузе // Культура, наука, образование: проблемы и перспективы. 2015. С. 470-473.

2. Тарева Е.Г. Концептуальные основы учебника по профессиональной коммуникации для подготовки лингвистов // Вестник Бурятского государственного университета. 2009. № 15. С. 246-250.

3. Евдокимова М.Г. Профессионально ориентированное обучение иностранным языкам в неязыковом вузе как система // Вестник Московского государственного лингвистического университета. Серия: Образование и педагогические науки. 2013. № 12 (672). С. 49-58.

4. Голованова Е.И. Профессиональный дискурс, субдискурс, жанр профессиональной коммуникации: соотношение понятий // Вестник Челябинского государственного университета. 2013. № 1 (292). С. 3235.

5. Аниськин В.Н., Богословский В.И., Жукова Т.А. Социокультурная компетентность преподавателя высшей профессиональной школы: особенности формирования: учебно-методическое пособие для преподавателей и студентов педагогических вузов. Самара; СПб.: ПГСГА, 2011. 172 с.

6. Голованова Е.И. Типология единиц профессиональной коммуникации: когнитивно-прагматический аспект // Вестник Челябинского государственного университета. 2008. № 9. С. 25-28.
7. Горюнова Е.С. Критерии отбора текстов для обучения студентов неязыковых вузов иноязычному профессионально ориентированному чтению // Вестник Томского государственного педагогического университета. 2011. № 2. С. 60-64.

8. Васильева 3.С. Опыт исследования коммуникативного взаимодействия, опосредованного видеотехнологиями // Антропологический форум. 2010. № 13. C. $177-210$.

9. Осипов А.В. Особенности эвфемизации в профессиональной коммуникации (на примере лексики медицины и силовых структур в русском и английском языках // Вестник Челябинского государственного университета. 2011. № 33. С. 109-111.

10. English for Sound Engineers: учебный практикум по английскому языку по специальности 070703.65 Звукорежиссура культурно-массовых представлений и концертных программ / сост. Н.В. Малова. Самара: СГИК, 2016. 65 с.

11. Разница между производителем и звукорежиссером [Электронный ресурс] // https://youtube. $\mathrm{com} /$ watch?v=lDBaTI32bMM.

12. Красивые Lies звукового дизайна. Тасос Fratzolas [Электронный pecypc] // https://youtube.com/ watch?v=jDy5j0c6TrU.

13. Контроль обработки живого звука через движение музыкантов [Электронный ресурс] // https://youtube.com/watch?v=eRo9412xYIY.

14. Вербицкий А.А. Контекстное обучение: теория и технологии // Новые методы и средства обучения. № 2 (16). Педагогические технологии контекстного обучения. М.: Знание, 1994. С. 3-57.

15. Буханцева Н.В., Дудина И.А. Модель электронного портфолио с использованием Google Sites для оценки результатов освоения программ бакалавриата // Образовательные технологии и общество. 2012. T. 15, № 2. С. 618-635.

\title{
PROFESSIONAL COMMUNICATION IN A FOREIGN LANGUAGE: DESIGNING A PRACTICAL WORKSHOP FOR BACHELORS
}

(C) 2017

\author{
Malova Natalia Vladimirovna, candidate of pedagogical sciences, \\ associate professor of Foreign Languages Department \\ Samara State Institute of Culture (Samara, Russian Federation)
}

\footnotetext{
Abstract. The following paper discusses the actual task of modern technical specialist training: getting him/her ready to communicate professionally in a foreign language. Practice requests are naturally reflected in the development of curricula and programs of higher professional education. The author demonstrates the urgency of the task in connection with the constantly changing foreign language professional communication, especially computermediated part of it. The author identifies two main approaches to the organization of studies at the university: changing the structure, content, methods of the course «Foreign Language» and the development of new courses of the curriculum. Within the framework of the second approach, the process of designing an educational and methodical complex for a professional communication course on the basis of a process approach is considered in some detail. The paper emphasizes the importance of using professional skills of prospective specialists to increase the effectiveness of the educational process, in particular, the development of copyright audio and video materials. The workshop for audio engineers, developed by the author of the paper, is successfully used in the educational process of Samara State Institute of Culture.

Keywords: methodical design; foreign language; bachelors training; interactive training; student thesaurus; professional communication situations; video content; sound engineer training; professional communication workshop in foreign language; audio-content; professional communication scenario; contextual approach.
} 